\title{
Leptin as an open secret in the physiopathology of rheumatic diseases
}

\author{
Mónica Vázquez-Del Mercado ${ }^{1,2,3}$ (D) Erika A. Martínez-García ${ }^{1,2,4} \mathbb{C}$
}

Received: 8 December 2019 /Revised: 15 December 2019 / Accepted: 19 December 2019 / Published online: 11 January 2020

(C) International League of Associations for Rheumatology (ILAR) 2020

It has been a long journey to understand the basic knowledge achieved about an intriguing molecule such as leptin, a molecule immersed in the deep ocean of study field of obesity, diabetes, metabolic syndrome, inflammation, and immune regulation. Since 1949, the phenotype of a mutated mouse leptin was identified with the $o b$ symbol resulting in diabetes and obesity, later known as $o b$ or lep gen [1]. In 1994, human leptin was cloned and sequenced with a mouse homology of $84 \%$ [2]. Leptin was biochemically characterized as a nonglycosylated $16 \mathrm{kDa}$ protein. Leptin signaling is mediated by its receptor isoforms from $a$ to $f$. In particular, the $e$ isoform is known as its soluble receptor (sLepR) [3]. Leptin is considering a hormone due to its pleiotropic actions and the identification of a circadian rhythm of secretion [4]. Leptin is synthesized mainly by adipose tissue and consider it as an adipokine member, between chemerin, visfatin, adiponectin (APN), high molecular weight adiponectin (HMW-APN), resistin, etc. [5]. The adipose tissue can be view as a noninflammatory or pro-inflammatory tissue, regarding the type of molecules studied. One of the hallmarks of a nonphysiological adipose tissue microenvironment is the polarizing macrophages response, favoring an M1 phenotype, where there is a predominance for the recognition of fatty free acids

Mónica Vázquez-Del Mercado dravme@hotmail.com

1 Instituto de Investigación en Reumatología y del Sistema Músculo-Esquelético, Centro Universitario de Ciencias de la Salud, Universidad de Guadalajara, Guadalajara, Jalisco, Mexico

2 UDG-CA-703 Inmunología y Reumatología, Centro Universitario de Ciencias de la Salud, Universidad de Guadalajara, Guadalajara, Jalisco, Mexico

3 Hospital Civil de Guadalajara "Juan I. Menchaca", Servicio de Reumatología, 004086, PNPC, CONACyT, Sierra Mojada no.950, Colonia Independencia, 44340 Guadalajara, Jalisco, Mexico

4 Departamento de Fisiología, Centro Universitario de Ciencias de la Salud, Universidad de Guadalajara, Guadalajara, Jalisco, Mexico through Toll-like receptors (TLR) 2 and TLR 4 and a proinflammatory cytokine response (Th1) mediated by NFkB, triggering an unfolded protein response by of endoplasmic reticulum stress, chemokine secretion, and activation of $\mathrm{B}$ and $\mathrm{T}$ cells $[6,7]$. To review leptin influence as a triggering molecule in a myriad of chronic diseases is of key importance to establish this minimum background. There are several studies that highlighted the role of leptin in chronic inflammatory processes such as obesity, diabetes, and metabolic syndrome to name a few, and it has become an open secret its participation in autoimmune rheumatic diseases. However, its recognition as a possible key biomarker in immunopathogenic mechanisms of diseases such as systemic lupus erythematosus (SLE), rheumatoid arthritis (RA), and ankylosing spondylitis (AS) has been delayed [8-10]. Nowadays, we are able to talk about leptin network microenvironments, depending on the target tissue, for example, adipose tissue in obesity, synovial tissue in RA, renal tissue in SLE, and bone tissue in AS. With this scenario, in this Editorial, we are going to discuss briefly leptin role key points in autoimmune rheumatic diseases. It is important to highlight the heterogeneity on leptin measurements in human studies on rheumatic diseases, mainly due to the lack of reliability of assays used to measure circulating leptin, the circadian clock and the time of the day when sample was taken, the disease duration, the activity index of the disease, ethnicity, age, corporal composition, body mass index, tissue fat mass redistribution, metabolic markers evaluated, etc. In general, it has been shown that in RA patients, leptin levels are increased, but with controversy related to its association with clinical disease activity and worse prognosis [11, 12]. We reported in 2015, a group of RA patients without cardiovascular or metabolic comorbidities or previous nutrition state evaluation. We were able to report that in pre-obese and obese RA patients, there was increased production of serum leptin associated with anti-CCP antibodies positivity. This conclusion was achieved after normalization of the ratio of serum leptin and fat mass [13]. In contrast in AS, there are contradictory reports ranging from decreased serum leptin 
levels in AS without comorbidities such as diabetes mellitus, hypertension, dyslipidemia, and obesity to non-significant differences in leptin levels in AS versus control subjects $[14,15]$. Notwithstanding, in a leptin deficient $(o b / o b)$ mouse model, it was proved a potential differential effect of leptin in mineral bone mineral density, according to the skeleton area evaluated [16]. The pleiotropic role of leptin seems to be related to its central or peripheral regulation. Leptin influences the differentiation of bone marrow stem cells into osteoblasts, osteoclasts, or adipocytes. It is interesting to read about the results of a potential protective role of leptin and high molecular weight adipokine (HMW-APN) in women patients with AS. These patients exhibited higher leptin levels and HMW-APN with less radiographic spinal progression, suggesting a protective role of these adipokines [17]. But, what about the role of leptin in osteoarthritis (OA), the most prevalent rheumatic disease? Since the experience of pain is the cardinal symptom in OA, Gandhi et al. in 2010 applied The Western Ontario and McMaster Universities Arthritis Index (WOMAC) pain scale, which evaluates functional activity pain, and the Short Form McGill Pain Questionnaire (MPQ-SF) that describes characteristics and severity of pain in knee OA patients. In addition, serum and synovial fluid levels of APN, leptin and its ratio (A/L) were studied. The data achieved allow us to learn that the $\mathrm{A} / \mathrm{L}$ ratio predicts better the pain experience using the MPQ-SF. Gandhi et al. talked about a possible cross-talk between APN and leptin between serum and synovial fluid in $\mathrm{OA}$, since the levels measured of these adipokines resulted quite close [18]. Another study done on severe knee OA patients reported a non-significant difference of leptin, HMWAPN, resistin, and ghrelin measured at serum, when compared with healthy subjects. However, total-APN was found to be higher when it associates to fat mass redistribution, particularly in abdominal area. In general, leptin has been reported to be elevated at serum levels, but it remains contradictory to its potential role as a severity biomarker of joint damage in OA [19]. In the present issue of this journal, Yuan et. al conducted a review of the literature focused on the leptin role in SLE on different types of immune cells in both, innate and adaptive immunity. The authors highlighted the macrophage, as a central actor involved in tolerance lost mediated by a delayed phagocytosis, resulting in inefficient removal of apoptotic material, which leads to its identification as foreign antigens waking up an autoimmune response against our own cellular components. Another important aspect mentioned by the authors is the participation of M1 macrophage phenotype as a trigger of inflammation associated with IL- 6 , TNF- $\alpha$, and IFN- $\gamma$ secretion and lupus nephritis. A source of auto-antigen also is the production of neutrophil extracellular traps (NETs); however, the direct relationship of leptin with these mechanisms is not fully understood. Notwithstanding, neutrophil apoptosis has been found to correlate with SLE disease severity. The authors emphasize the participation of $\mathrm{T}$ cells in the pathogenesis of SLE and comment that leptin function as a survival factor, since it delays the apoptosis of $\mathrm{T}$ cells by expression of $\mathrm{Bcl}-2$. It is well known that a factor related to $\mathrm{T}$ cells in SLE is the production of pro-inflammatory cytokines, and in this review, they showed that on leptindeficient mice, there is a decrease production of Th1 cytokines but increase in Th2 anti-inflammatory profile. Also Yuan et al. remarked the importance of Th17 subpopulations in newonset SLE patients. In mouse models, the findings on deficient LepR were characterized by a decrease differentiation of $\mathrm{T}$ cells to Th17, due to the decrease in the activation of STAT3 signaling, suggesting the importance of LepR for Th17 differentiation. In addition, leptin causes the exacerbation of inflammation as it interacts with IL-6/TGF- $\beta$ or by inducing of ROR $\gamma \mathrm{T}$ expression, which promotes Th17 responses in SLE. Another subpopulation of cells affected by leptin is Treg cells. In vitro models shown that leptin decreases the immunosuppression capabilities of Treg cells, reflecting that leptin is related to the pathogenesis of SLE. Finally, leptin in SLE is one of the most important orchestrators in the immunopathology on B cells as autoantibodies producers. In summary, Yuan et al. in this review proposed that leptin could be studied as a possible therapeutic target or consider it as a new severity biomarker in SLE, which must be elucidated in the near future [20].

\section{Compliance with ethical standards}

Disclosures None.

\section{References}

1. Ingalls AM, Dickie MM, Snell GD (1950) Obese, a new mutation in the house mouse. J Hered 41(12):317-318. https://doi.org/10. 1093/oxfordjournals.jhered.a106073

2. Zhang Y, Proenca R, Maffei M, Barone M, Leopold L, Friedman JM (1994) Positional cloning of the mouse obese gene and its human homologue. Nature 372(6505):425-432. https://doi.org/10. $1038 / 372425 \mathrm{a} 0$

3. Wauman J, Zabeau L, Tavernier J (2017) The leptin receptor complex: heavier than expected? Front Endocrinol (Lausanne) 8:30. https://doi.org/10.3389/fendo.2017.00030

4. Vadacca M, Margiotta DP, Navarini L, Afeltra A (2011) Leptin in immuno-rheumatological diseases. Cell Mol Immunol 8(3):203212. https://doi.org/10.1038/cmi.2010.75

5. Raucci R, Rusolo F, Sharma A, Colonna G, Castello G, Costantini S (2013) Functional and structural features of adipokine family. Cytokine 61(1):1-14. https://doi.org/10.1016/j.cyto.2012.08.036

6. Kratz M, Coats BR, Hisert KB, Hagman D, Mutskov V, Peris E, Schoenfelt KQ, Kuzma JN, Larson I, Billing PS, Landerholm RW, Crouthamel M, Gozal D, Hwang S, Singh PK, Becker L (2014) Metabolic dysfunction drives a mechanistically distinct proinflammatory phenotype in adipose tissue macrophages. Cell Metab 20(4):614-625. https://doi.org/10.1016/j.cmet.2014.08.010

7. Miani M, Colli ML, Ladriere L, Cnop M, Eizirik DL (2012) Mild endoplasmic reticulum stress augments the proinflammatory effect of IL-1beta in pancreatic rat beta-cells via the IRE1alpha/XBP1s 
pathway. Endocrinology 153(7):3017-3028. https://doi.org/10. 1210/en.2011-2090

8. Hrycek E, Banasiewicz-Szkrobka I, Zurakowski A, Dworak J, Blaszczak E, Franek A, Buszman P (2018) Selected adipokines and thickness of the intima-media complex in patients with systemic lupus erythematosus. Kardiol Pol 76(5):917-919. https://doi.org/ 10.5603/KP.2018.0099

9. Guimaraes M, de Andrade MVM, Machado CJ, Vieira ELM, Pinto M, Junior ALT, Kakehasi AM (2018) Leptin as an obesity marker in rheumatoid arthritis. Rheumatol Int 38(9):1671-1677. https://doi. org/10.1007/s00296-018-4082-5

10. Rademacher J, Tietz LM, Le L, Hartl A, Hermann KA, Sieper J, Mansmann U, Rudwaleit M, Poddubnyy D (2019) Added value of biomarkers compared with clinical parameters for the prediction of radiographic spinal progression in axial spondyloarthritis. Rheumatology (Oxford) 58(9):1556-1564. https://doi.org/10.1093/ rheumatology/kez025

11. Tian G, Liang JN, Pan HF, Zhou D (2014) Increased leptin levels in patients with rheumatoid arthritis: a meta-analysis. Ir J Med Sci 183(4):659-666. https://doi.org/10.1007/s11845-014-1072-9

12. Bustos Rivera-Bahena C, Xibille-Friedmann DX, GonzalezChristen J, Carrillo-Vazquez SM, Montiel-Hernandez JL (2016) Peripheral blood leptin and resistin levels as clinical activity biomarkers in Mexican rheumatoid arthritis patients. Reumatol Clin 12(6):323-326. https://doi.org/10.1016/j.reuma.2015.11.011

13. Gomez-Banuelos E, Navarro-Hernandez RE, Corona-Meraz F, Madrigal-Ruiz PM, Martin-Marquez BT, Pizano-Martinez OE, Aguilar-Arreola J, Perez-Cruz PJ, Macias-Reyes H, GonzalezLopez L, Gamez-Nava JI, Salazar-Paramo M, Vazquez-del Mercado M (2015) Serum leptin and serum leptin/serum leptin receptor ratio imbalance in obese rheumatoid arthritis patients positive for anti-cyclic citrullinated peptide antibodies. Arthritis Res Ther 17:335. https://doi.org/10.1186/s13075-015-0850-8
14. Mei YJ, Wang P, Chen LJ, Li ZJ (2016) Plasma/serum Leptin levels in patients with ankylosing spondylitis: a systematic review and meta-analysis. Arch Med Res 47(2):111-117. https://doi.org/10. 1016/j.arcmed.2016.03.001

15. Sari I, Demir T, Kozaci LD, Akar S, Kavak T, Birlik M, Onen F, Akkoc N (2007) Body composition, insulin, and leptin levels in patients with ankylosing spondylitis. Clin Rheumatol 26(9):14271432. https://doi.org/10.1007/s10067-006-0509-6

16. Hamrick MW, Pennington C, Newton D, Xie D, Isales C (2004) Leptin deficiency produces contrasting phenotypes in bones of the limb and spine. Bone 34(3):376-383. https://doi.org/10.1016/j. bone.2003.11.020

17. Hartl A, Sieper J, Syrbe U, Listing J, Hermann KG, Rudwaleit M, Poddubnyy D (2017) Serum levels of leptin and high molecular weight adiponectin are inversely associated with radiographic spinal progression in patients with ankylosing spondylitis: results from the ENRADAS trial. Arthritis Res Ther 19(1):140. https://doi.org/ 10.1186/s 13075-017-1350-9

18. Gandhi R, Takahashi M, Smith H, Rizek R, Mahomed NN (2010) The synovial fluid adiponectin-leptin ratio predicts pain with knee osteoarthritis. Clin Rheumatol 29:1223-1228. https://doi.org/10. 1007/s10067-010-1429-z

19. Toussirot E, Michel F, Béreau M, Dehecq B, Gaugler B, Wendling D, Grandclément E, Saas P, Dumoulin G (2017) Serum adipokines, adipose tissue measurements and metabolic parameters in patients with advanced radiographic knee osteoarthritis. Clin Rheumatol 36: 2531-2539. https://doi.org/10.1007/s10067-017-3789-0

20. Yuan Q, Chen H, Li X, Wei J (2019) Leptin: an unappreciated key player in SLE. Clin Rheumatol. https://doi.org/10.1007/s10067019-04831-8

Publisher's note Springer Nature remains neutral with regard to jurisdictional claims in published maps and institutional affiliations. 